\title{
Introduction
}

\section{Introduction: Air Pollution in China}

\author{
Kristin Aunan ${ }^{*}$, Mette Halskov Hansen ${ }^{\dagger}$ and Shuxiao Wang*
}

\begin{abstract}
This introduction provides an overview and analysis of key scientific data regarding air pollution in China. It constitutes a reference for understanding how policymakers, media and population in China make sense of and deal with air pollution, as discussed in the other articles of the section. We summarize the major characteristics and trends regarding air pollution in China, including its main sources and composition, levels of population exposure across the country, attributable mortality, and mitigation efforts. We also compare current levels of air pollution in China with other parts of the world and in a historical perspective. While the situation remains dire in many regions, particularly the Northeast, we conclude that there are signs of relief, or at least a halt to the increase in ambient air pollution levels. At the same time, critical issues regarding unequal levels of exposure remain, and health damaging levels of air pollution in cities will undoubtedly remain high for a long time to come. The rural population residing in areas close to industry and polluted cities and still depending on solid household fuels will likely be the worst off when it comes to air pollution exposure.
\end{abstract}

Keywords: scientific data on air pollution; household air pollution; air pollution abatement measures; Chinese smog

\begin{abstract}
"Clean air for sale in China" was the title of one of many recent news articles describing a double-digit growth in the sale of air purifiers in China. ${ }^{1}$ The market for devices that help keep indoor air clean by filtrating outdoor air before it enters the dwelling has sky rocketed since 2013 along with increasing use of face masks - now even available in fashionable patterns - meant to protect
\end{abstract}

* CICERO Center for International Climate Research and University of Oslo.

$\dagger$ University of Oslo. Email: m.h.hansen@ikos.uio.no (corresponding author).

* Tsinghua University. All co-authors contributed equally to the research and share lead authorship.

1 Nelson, Christina. 2014. "Clean Air for Sale in China." China Business Review, 7 February, http://www. chinabusinessreview.com/clean-air-for-sale-in-china/. Accessed 18 April 2016. 
people from breathing polluted air. ${ }^{2}$ A growing number of private schools in Beijing erect fabric domes over their campuses to provide clean air for students, and companies in the capital report that executive hiring has become more difficult due to poor air quality. ${ }^{3}$ The boom in the market for air filtrating devices coincides with intensified media attention on air pollution that again suggests that a rapidly increasing number of Chinese citizens perceive pollution as an important health risk to themselves and their children. At the same time, we are seeing unprecedented attempts by the Chinese government to tackle the growing problem of air pollution without compromising continued economic growth.

The articles in this special section grow out of an interdisciplinary research project in which scholars from the humanities, social sciences and natural sciences together study how government, scientists, media, industry and the population of China try to make sense of and deal with the increased sense of risk related to the impact of air pollution on health, climate, economy and political stability. ${ }^{4}$ To what extent is a general rise of concern for air pollution justified by the actual pollution levels seen in major Chinese cities in recent years? What is happening on the ground, where people have to live with new knowledge of what air pollution does to their health? Do we really see a rising environmental consciousness in China, and if so, what does that mean and how is it expressed? Based on the analysis of new empirical data, each of the articles in this issue offers at least partial answers to one or several of these questions. Common to all the articles is the interest in understanding if, how and to what extent political authorities, media, the general population and polluting enterprises in China interact in the face of the acknowledged risks that air pollution poses to the local environment, China's economic development and, not least, individual health and well-being.

The point of departure for Anna L. Ahlers and Yongdong Shen is the theory of authoritarian environmentalism and its application to the China case. ${ }^{5}$ The existing literature argues that while the central government is able to effectively and rapidly introduce new environmental policies, the implementation of these is often hampered, even sabotaged, at the local level. In their in-depth analysis of how China's new air policies are translated into government initiatives at the local level in Hangzhou city, Ahlers and Shen show that local authorities in fact do work to implement air pollution regulation measures. The authors discuss under which conditions the local state engages in experiments with both coercive decision-making processes and with different forms of public inclusion. This analysis of local authoritarian environmentalism sets the political frame for the

2 TechSci Research. 2015. "China Air Purifiers Market Forecast and Opportunities, 2020,” May, http:// www.techsciresearch.com/report/china-air-purifiers-market-forecast-and-opportunities-2020/416.html. Accessed 18 April 2016.

3 Zheng 2015.

4 The project "Airborne: Pollution, Climate Change and New Visions of Sustainability" (http://www.hf. uio.no/ikos/english/research/projects/airborne-pollution-china/index.html) runs from 2015 to 2019 with generous financial support from the Research Council of Norway and the Norwegian Centre for Advanced Study, Norway.

5 Ahlers and Shen 2017 (this issue). 
further exploration of interfaces of government, media and population, and of dominant discourse and popular practices related to air pollution, discussed in the other articles of the section.

Thus, the article by Hongtao $\mathrm{Li}$ and Rune Svarverud analyses the ways in which the Chinese media have sought to frame the issue of air pollution in a politically acceptable, though far from uncritical way. ${ }^{6}$ In a historically grounded study, the authors show how the media have effectively used the famous "London Smog" to paint a picture of the Chinese present set against the backdrop of a foreign past. The unprecedented media interest in air pollution since 2012 has reached into all corners of the country, and people's concern with the health impact of industrial air pollution has to an increasing extent found support in these reports, as well as in new air pollution policies. Based on a combination of ethnographic fieldwork and household surveys, two articles in this special section discuss in more detail how residents in urban and rural China have come to understand and respond to these perceived risks of air pollution. In a survey among urban residents in one of China's notoriously polluted cities, Tangshan in Hebei province, Xiaoyue Li and Bryan Tilt ${ }^{7}$ found that middle-class citizens expressed a holistic view of what a good life implied, and they persistently ranked "environmental quality," as linked to their own and their children's health, higher than job and income. Even the majority of the much less affluent rural residents in the study by Mette Halskov Hansen and Zhaohui Liu reported that they found environmental protection to be more important than economic development. ${ }^{8}$ Villagers had been protesting for years against local sources of air pollution, but unlike their urban fellow citizens they had no access to scientific data about the actual air quality in their community. Nevertheless, protests were justified by the political imaginary of Ecological Civilization that aims at a heightened environmental consciousness of the whole population while stressing "harmony" and "social stability."

One of the questions that frequently turned up during the ethnographic data collection leading to this section's articles was simply what we, as scholars, actually know about the air quality and its human impact in different areas of China, and whether or not things are improving. As a context for these articles, and a background for anybody interested in the social and political aspects of air pollution in China, we therefore aim in the following to review existing scientific data on air pollution in China in an attempt to summarize what the situation is, has been, as well as what the future may hold. We examine how the air quality in China compares with other countries, and probe into parameters that define the air pollution challenge in China, from emissions and concentration levels and further on to their impacts on human health. We also challenge the perception that air pollution is something that affects everybody equally. Clean air from

8 Hansen and Liu 2017 (this issue). 
Canada and Norway is now literally for sale in China, ${ }^{9}$ but, more importantly, there are a number of socio-economic factors that affect an individual's exposure to air pollution and thereby modify the health risk. One of the more significant examples of structural differences between rural and urban, and between poorer and richer population groups, concerns the exposure to air pollution from the use of wood and coal in residential cooking and heating stoves which may be present in addition to other forms of ambient air pollution. This topic is taken up in the article by Hansen and Liu who found that villagers were not at all concerned with the possible impact of this kind of household-produced air pollution, although they were protesting vehemently against air pollution from local industry. Keeping in mind that "the dose is the demon," 10 we discuss in what follows how different sources of population exposure have changed in China's recent history.

\section{"Chinese Haze": The Worst of Both Worlds?}

Historically, recurring episodes of extremely severe air pollution within one location have led to special terminology of the phenomenon. The "London fog" or "London pea-souper" thus denoted the thick layer of air pollution that covered London repeatedly during winter months in the 19th and early 20th centuries, culminating with the London smog disaster in 1952 that caused between 4,000 and 12,000 deaths. ${ }^{11}$ In textbooks this is often referred to as "London-type smog" or "classical smog." It is characterized by a high content of sulphur oxides, carbon monoxide (CO) and soot particles, and is caused by the use of fossil fuels with a high sulphur content, the most important being coal. In London, the air pollution became particularly bad due to the widespread use of bituminous coal for heating in combination with a humid climate and stagnant winter weather conditions. As discussed in the article by $\mathrm{Li}$ and Svarverud, the London smog was introduced in Chinese media already in the 1870s. Interestingly, nearly 150 years later, in the 2010s, it came to play a renewed role in Chinese media's construction of a historical analogy suggesting that a world famous foreign city in the past had been just as bad - or worse - off than Chinese cities in the present.

Another main smog archetype is the "Los Angeles-type smog," or "photochemical smog." Photochemical ${ }^{12}$ smog, first brought to the world's attention in the 1940s based on episodes in Los Angeles, requires neither smoke nor fog and typically occurs during summer in urban areas where a large number of cars are emitting nitrogen oxides and hydrocarbon vapours. Ozone, a highly

9 http://www.tnp.no/norway/panorama/5357-selling-fresh-premium-mountain-air-from-norway-to-chinaon-ebay. Accessed 5 November 2016.

10 A condensed version of Paracelsus' (1493-1541) famous observation on the toxicological properties of chemicals.

11 Austin, Brimblecombe and Sturges 2002.

12 The word "photochemical" implies that solar radiation is essential for pollution to build up. 
reactive oxidant that adversely affects the respiratory system, is a key component of photochemical smog. Both the London and the Los Angeles types of smog reduce visibility, the former usually much more than the latter. ${ }^{13}$ Beyond these two archetypes, a range of other mixtures and characteristics of air pollution may occur, depending on emission sources and physio-chemical conditions.

In China, polluting industries, an energy sector dominated by coal, rapidly increasing motorization, in combination with a continued use of wood and coal in simple stoves in hundreds of millions of homes along with open burning of crop wastes in agricultural fields, have contributed to a complex air pollution situation. ${ }^{14}$ Depending on season and climate, some regions are experiencing both "classical" and "photochemical" smog, in addition to other types of anthropogenic and natural air pollution phenomena such as smoke from biomass burning and desert dust. ${ }^{15}$ For instance, Shijiazhuang, the capital of Hebei province, had the highest or close to the highest annual mean readings for all air pollutants monitored in the national air pollution monitoring programme in 2013, including fine particulate matter $\left(\mathrm{PM}_{2.5}\right)$, sulphur dioxide $\left(\mathrm{SO}_{2}\right)$, nitrogen dioxide $\left(\mathrm{NO}_{2}\right)$, and surface ozone $\left(\mathrm{O}_{3}\right)$. The region-wide haze blanketing Shijiazhuang and many other cities as well as rural areas in China has in recent years been commonly referred to as haze (mai 䨱) or smog (wumai 雾䨪). ${ }^{16}$

Haze is by definition a phenomenon that entails low atmospheric visibility and is mainly caused by the fine fraction of particles, which contribute to light extinction through scattering or absorption of visible light. ${ }^{17}$ Thus, the sharp reduction in visibility observed in many megacities in China bears witness to the increased loading of fine fraction particles, often measured as $\mathrm{PM}_{2.5}$, in ambient air. ${ }^{18} \mathrm{As}$ we discuss below, this is the air pollution component thought to be most closely linked to severe health damage, including premature death. As a pollution phenomenon, "haze" is not an unambiguous term, however, and studies attempting to describe the sources and physio-chemical nature of haze episodes in Chinese cities show a varying picture depending on place and time.

Regarding the relative contribution of various source categories to urban $\mathrm{PM}_{2.5}$ pollution, traffic currently plays a smaller role in China than in the US, Western Europe and Japan, with an estimated 15-18 per cent of pollution in China resulting from traffic versus $21-35$ per cent in the US, Western Europe, and Japan (a lower figure, 19 per cent, was estimated for Central and Eastern Europe). Industry, on the other hand, generally plays a larger role in China, constituting 16-27 per cent of the $\mathrm{PM}_{2.5}$ pollution versus 9-13 per cent in the US and Western Europe (higher figures were estimated for Central and Eastern Europe

13 Zhang and Samet 2015.

14 Wang and Hao 2012.

15 Wang, Xing et al. 2014.

16 See Li and Svarverud 2017 (this issue) on how and when these concepts came into Chinese discourse.

17 Particles with a size of about $0.4-1 \mu \mathrm{m}$ in aerodynamic diameter have the highest light extinction potential.

18 Cheng, Wang et al. 2013. 
(17 per cent) and Japan (34 per cent). ${ }^{19}$ Regarding the chemical composition, the air pollution mixture in China is richer in sulphur oxides and nitrogen oxides compared to the typical air pollution in developed countries, as these gases have not been abated to the same extent. ${ }^{20}$ Soot, often measured as black carbon and a component in the $\mathrm{PM}_{2.5}$ size range, is also more prominent in the air pollution mixture in many parts of China as compared to, for instance, the US and Western Europe. ${ }^{21}$ The reason is a combination of household air pollution caused by the use of biomass and coal for cooking and heating, and older technology used in some industries.

According to Chinese census data, nearly half of households primarily used solid fuels for cooking in 2010, and four out of five of these households were in rural areas (Figure 1). ${ }^{22}$ Burning of wood, crop residues and coal in simple household stoves leads to the incomplete combustion of the fuel, meaning less heat is produced per kilogram of fuel used. Instead of producing heat (and $\mathrm{CO}_{2}$, the main product of complete combustion), some of the fuel carbon is converted to particles, carbon monoxide, and a range of toxic organic components. ${ }^{23}$ Approximate 0.6 billion people are using solid fuels on a regular basis in their homes, thereby contributing an estimated 38 per cent of primary $\mathrm{PM}_{2.5}$ emissions in 2010, on par with the emissions from industry (41 per cent). ${ }^{24}$ Estimates of the contribution from household stoves to average population-weighted exposure to ambient $\mathrm{PM}_{2.5}$ in China are in the range $10-20$ per cent. ${ }^{25}$

The largest exposures to air pollution from cooking and heating with solid fuels are, however, not related to their contribution to ambient air pollution but rather to indoor pollution (denoted household air pollution, or HAP, by the World Health Organization [WHO]). This is due to the fact that most people spend many hours indoors in their home, and that burning of solid fuels in traditional stoves leads to high PM concentrations close to peoples' breathing zone. Thus, the fraction of the total emitted particles that ends up being inhaled is much higher for this pollution source compared to emissions from high smoke stacks.

19 Karagulian et al. 2015.

20 Emissions of $\mathrm{SO}_{2}$ in 33 European countries decreased by 74 per cent between 1990 and 2011. See EEA (European Environmental Agency). 2015. "Sulphur dioxide $\left(\mathrm{SO}_{2}\right)$ emissions," 4 September, http://www. eea.europa.eu/data-and-maps/indicators/eea-32-sulphur-dioxide-so2-emissions-1/assessment-3. Accessed 18 April 2016.

21 Wang, Rong et al. 2014.

22 NBS 2012. Population Census Office under the State Council and Population and Employment Statistics Department of the National Bureau of Statistics of China, 2012. Tabulation on the 2010 population census of the People's Republic of China. 2012: China Statistics Press. Table 9-3a Number of households according to facility (city) (in Chinese). http://www.stats.gov.cn/tjsj/pcsj/rkpc/6rp/indexch. htm. Accessed 26 April 26. Duan et al. 2014 in their survey present data for main cooking fuels for 2011/2012. On the aggregate, their data compare well with the China Census data (32 per cent of homes used biomass, 11 per cent used coal).

23 Naeher et al. 2007.

24 Stohl et al. 2015.

25 Karagulian et al. 2015; Chafe et al. 2014. Higher contributions are estimated for the Beijing-TianjinHebei region, see Liu et al. 2016. 
Figure 1: Main Household Cooking Fuels in the Chinese Population in 2010 (Million People)

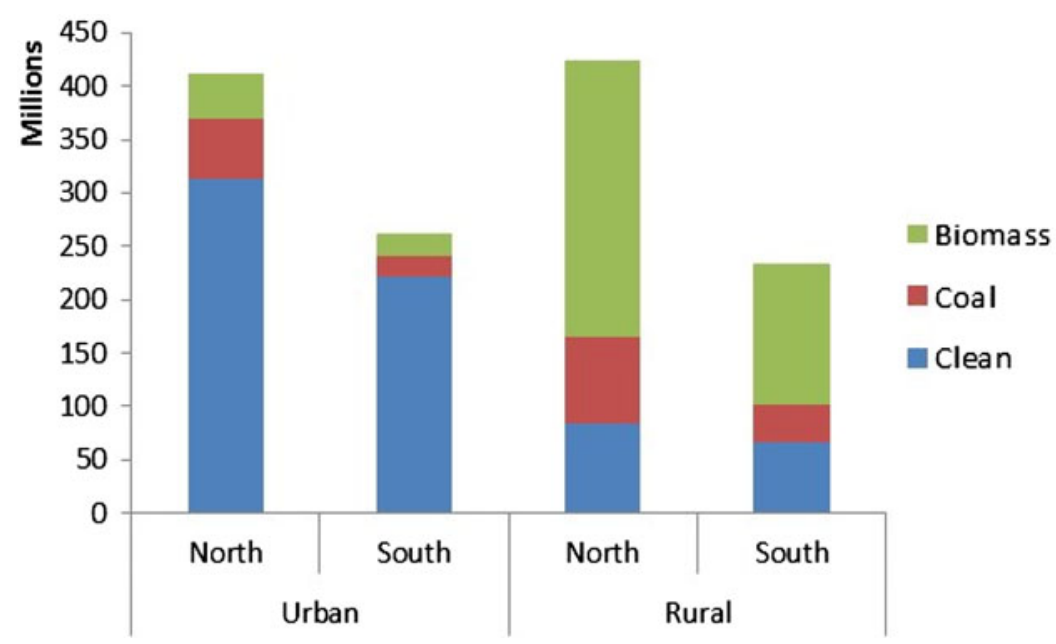

As discussed below, estimates of population-weighted exposure to ambient air pollution in China are becoming increasingly more robust due to the rapidly expanding urban $\mathrm{PM}_{2.5}$ monitoring network and the opportunity to use satellite data. The situation regarding exposure to HAP is different. Due to the lack of air quality monitoring in rural areas in China and the intrinsically larger difficulties in obtaining data on indoor pollution, the basis for estimating exposure for population groups dependent on solid household fuels is limited. In a global review of the evidence related to $\mathrm{PM}_{2.5}$ exposure from HAP, the pooled mean exposure was about $270 \mu \mathrm{g} / \mathrm{m}^{3}$ for women and about $220 \mu \mathrm{g} / \mathrm{m}^{3}$ for children (there were few studies on male exposure to HAP). ${ }^{26}$ Studies in China and elsewhere indicate that biomass users generally have a higher exposure to $\mathrm{PM}_{2.5}$ than coal users. ${ }^{27}$ On the other hand, high cancer rates have been linked to the use of "smoky coal" in Chinese villages. ${ }^{28}$ Available data from China indicate that annual average exposure to $\mathrm{PM}_{2.5}$ among solid fuel-using populations is in the range of $100-400 \mu \mathrm{g} / \mathrm{m}^{3} .{ }^{29}$ That is on par with, or considerably higher than, the annual mean level in the most polluted Chinese cities, something which is, however, rarely discussed in Chinese media and policy documents.

The use of household stoves seems to be rapidly decreasing in China as more and more people have access to, and can afford, cleaner fuels such as gas and electricity. Whereas certain policies have been implemented to promote a switch

26 WHO 2014. Indoor Air Quality Guidelines: Household Fuel Combustion. http://www.who.int/ indoorair/guidelines/hhfc/en/. Accessed 26 April 2016.

27 Alnes et al. 2014.

28 Zhao et al. 2006; Lan et al. 2002; Seow et al. 2014.

29 Mestl et al. 2007; Aunan and Wang 2014, Li et al. 2016. 
in household fuel use, such as banning the use of household coal in cities and subsidy programmes for biogas digesters in rural areas, urbanization in general, and massive rural-urban migration in particular, are likely the most important reasons for the fuel transition. ${ }^{30}$ Therefore, poor urban residents without access to clean household fuels are now most likely the worst off in terms of air pollution exposure, being subject both to HAP and polluted urban air. Also, a recent study found that rural residents living close to polluted cities in fact were also more likely to suffer the detrimental impacts of smog episodes. ${ }^{31}$

Exposure to particulate pollution has been linked to many diseases, including cardiovascular and respiratory diseases, diabetes, and neurodevelopment and cognitive impairment. ${ }^{32}$ According to estimates for China, there were about 1.5 million premature deaths attributable to $\mathrm{PM}_{2.5}$ exposure in 2015 , of which about 60 per cent were due to ambient $\mathrm{PM}_{2.5}$ pollution and about 40 per cent to HAP. ${ }^{33}$ Thus, while contributing a limited share of the emissions of $\mathrm{PM}_{2.5}$ and its precursors, the burning of biomass and coal in household stoves contributes disproportionately to health damage due to the high exposures among certain population groups. An additional 0.07 million deaths were attributed to ambient ozone exposure. Air pollution-related deaths in total constituted 17 per cent of total annual deaths in 2015, among the highest in the world. In China, as in nearly all countries in the world, the rate of annual deaths attributable to HAP has been decreasing. The rate of deaths attributable to air pollution in total in 2015 (i.e. including ambient $\mathrm{PM}_{2.5}$, ozone and HAP) is estimated at about 115 deaths per 100,000 people. For comparison, the estimated figure for India was 138 deaths per 100,000 people, 49 in Japan, 43 in Western Europe and 31 in the US. ${ }^{34}$

\section{Comparison across Space and Time}

Even though there are some differences in sources and composition of air pollution in China and developed countries, the largest difference is probably the mere concentration levels of pollutants, especially of particulate pollution. In most developed countries, the annual mean population-weighted exposure to $\mathrm{PM}_{2.5}$ has steadily decreased. In the US, Western Europe and Japan, for instance, it is now estimated to be below approximately $15 \mu \mathrm{g} / \mathrm{m}^{3}$ as an average, and reaching up to $40 \mu \mathrm{g} / \mathrm{m}^{3}$ only in very limited regions, for example, in Eastern European countries

30 Aunan and Wang 2014.

31 Zhou et al. 2015.

32 WHO (World Health Organization). 2013. "Health effects of particulate matter: Policy implications for countries in eastern Europe, Caucasus and Central Asia," http:/www.euro.who.int/_data/assets/pdf_file/0006/ 189051/Health-effects-of-particulate-matter-final-Eng.pdf. Accessed 24 April 2016; Calderon-Garciduenas et al. 2014; Lee et al. 2012.

33 Global Burden of Disease Study 2015 (GBD 2015) Data Resources. Seattle, United States: Institute for Health Metrics and Evaluation (IHME), 2016. http:/ghdx.healthdata.org/gbd-data-tool. Accessed 27 October 2016.

34 Ibid. 
such as Poland, Romania, and Bulgaria, and in northern Italy. ${ }^{35}$ For China as a whole, the corresponding figure is around $55-60 \mu \mathrm{g} / \mathrm{m}^{3} \mathrm{PM}_{2.5}$, and in some regions of Eastern China it exceeds $100 \mu \mathrm{g} / \mathrm{m}^{3}$, i.e. the exposure is 2-7 times the levels observed in developed countries. ${ }^{36}$ During the most severe haze episodes, $\mathrm{PM}_{2.5}$ concentrations may be one or two orders of magnitude higher than urban levels in the US and Western Europe. ${ }^{37}$ This renders China among the top most polluted countries, above, for instance, Saudi Arabia, India, Pakistan and Nepal.

How then do the current air pollution concentrations in China compare with the "London smog" of 1952 and the "Los Angeles smog" in the 1960s? Comparisons are difficult to make due to discrepancies in measurement techniques and, for particulate matter, the components measured. However, rough comparisons suggest that the pollution levels even in the most polluted Chinese cities today seldom exceed the historical episodes as we know them. For instance, based on monitoring data for London for December 1952 (and the "normal" situation in 1951), ${ }^{38}$ it seems clear that $\mathrm{SO}_{2}$ concentrations in London at the time were considerably higher than in today's most polluted Chinese cities. The daily mean $\mathrm{SO}_{2}$ level averaged for all 12 monitoring stations in London in December 1952 reached nearly $2000 \mu \mathrm{g} / \mathrm{m}^{3}$ on the worst days (one station in Central London reached a daily mean of nearly $4000 \mu \mathrm{g} / \mathrm{m}^{3}$ ), and the monthly mean in December 1951 (a "normal" year) was about $650 \mu \mathrm{g} / \mathrm{m}^{3}$. Such high values have not been recorded even during haze episodes in the most polluted cities in China currently. For instance, the highest daily mean $\mathrm{SO}_{2}$ level in Shijiazhuang in the severe haze episode in January 2013 was $557 \mu \mathrm{g} / \mathrm{m}^{3}$ (more recent haze episodes had much lower levels), and the monthly mean was $268 \mu \mathrm{g} / \mathrm{m}^{3} .39$

Regarding particulate pollution, a comparison between London and Chinese cities is more complicated as PM in London was measured as black smoke (BS) at that time. The relationship between $\mathrm{BS}$ and $\mathrm{PM}_{10}$ (and $\mathrm{PM}_{2.5}$ ) may vary extensively with place and time (including season) and a conversion between the two is not recommended unless a validation study is available at a comparable site using comparable methods. To our knowledge, such validation is not available for London at this time. If we assume that the $\mathrm{PM}_{10} / \mathrm{BS}$-ratio is between $0.6-1.26,{ }^{40}$ this implies that the daily mean $\mathrm{PM}_{10}$ level averaged for all 12 monitoring stations in London in December 1952 reached $1000-2000 \mu \mathrm{g} / \mathrm{m}^{3}$ on the

35 Brauer et al. 2012; Apte et al. 2015; World Bank 2016.

36 These estimates cover urban and rural populations and are based on monitoring data, satellite data, and air pollution models, see Brauer et al. 2012; Apte et al. 2015; Zhang and Cao 2015; van Donkelaar et al. 2010; Brauer et al. 2016; World Bank 2016. Note that these values may not be representative for, e.g., the concentrations reached during air pollution episodes in urban areas.

37 Huang et al. 2014.

38 Wilkins 1954.

39 Based on hourly data downloaded from China National Environment Monitoring Center http://106.37. 208.233:20035/. Accessed 5 October 2016. Note that Beijing had lower readings than Shijiazhuang for both $\mathrm{SO}_{2}$ and particulate matter during the episode.

40 The lower estimate is based on Bell et al. 2001, who assume BS $\sim$ TSP and $\mathrm{PM}_{10} / \mathrm{TSP}=0.6$. The upper estimate is the ratio found by Hoek et al. 1997 in Katowice, Poland, in winter 1993/94 (when coal was still a common fuel for heating as well as in industry). 
worst days (and between $2700-5700 \mu \mathrm{g} / \mathrm{m}^{3}$ in Central London). The annual mean in Greater London 1952 was $270 \mu \mathrm{g} / \mathrm{m}^{3}$ for BS, i.e. a $\mathrm{PM}_{10}$ concentration of 160 $340 \mu \mathrm{g} / \mathrm{m}^{3}{ }^{41}$ In comparison, in Shijiazhuang, the highest daily mean $\mathrm{PM}_{10}$ concentration recorded during January 2013 was $1222 \mu \mathrm{g} / \mathrm{m}^{3}$, whereas the annual mean $\mathrm{PM}_{10}$ was $305 \mu \mathrm{g} / \mathrm{m}^{3}$ in 2013. In other words, the annual average levels of particulate pollution in China's most polluted cities may be on par with London in the early 1950s, and the peak values in recent episodes, while generally being lower, may possibly have touched the levels of the December 1952 "London smog." Regarding the "Los Angeles smog," the ozone $\left(\mathrm{O}_{3}\right)$ levels in Los Angeles were far above what is currently reported in China. For instance, hourly peak levels of nearly $1400 \mu \mathrm{g} / \mathrm{m}^{3} \mathrm{O}_{3}$ were measured when the "Los Angeles smog" was at its worst, and 20-40 per cent of the days in the larger Los Angeles region had hourly maximum levels above $1000 \mu \mathrm{g} / \mathrm{m}^{3}$ during the period 1956-1972.42 The mean value during summer (when $\mathrm{O}_{3}$ levels are the highest) was about $140 \mu \mathrm{g} / \mathrm{m}^{3}$. As a comparison, in Shanghai, Beijing, Shijiazhuang, and Guangzhou during 2013-2015 the maximum hourly level recorded was below around $360 \mu \mathrm{g} / \mathrm{m}^{3}$, and the highest mean value during summer (June to August) was $98 \mu \mathrm{g} / \mathrm{m}^{3}$ (recorded in Beijing in 2015).

Emissions of air pollutants in China primarily affect the country itself. However, long-range transport of polluted air masses also causes air pollution to increase in neighbouring countries. In Japan, it has been estimated that emissions in China contribute up to 50 per cent of the annual mean $\mathrm{PM}_{2.5}$ concentration in western parts of the country. ${ }^{43}$ Regarding surface ozone, the contribution from China was found to be up to 15 per cent during pollution episodes in Tokyo, on the eastern coast of the country. ${ }^{44}$ Similarly, China is shown to be a major source region affecting pollution levels in Korea. ${ }^{45}$ Trans-Pacific transport of air pollution from China to the western coast of the US has long been recognized as a salient political issue, as it may contribute to violation of health-based US air quality standards in a situation where the US's own emissions are subject to continuously stricter regulations. ${ }^{46}$ However, one reason for the differing levels of air pollution between China and Western countries is the outsourcing of manufacturing industries that has taken place as pollution policies were tightened in Europe and the US mainly since the 1970s. ${ }^{47}$ For instance, during the period 1997-2010 it was estimated that the export of goods was the only final-demand category that drove the growth in emission of primary $\mathrm{PM}_{2.5}$ in China. The export-linked emission growth over the period corresponded to half the total emission in EU-27 countries in 2010.48 


\section{Geographical Variations and National Trends}

While China is home to some of the most polluted cities on earth, there are substantial differences across the country, due to varying emission intensity, meteorological conditions, and the impact of dust storms. The highest pollution levels and occurrence of haze episodes, i.e. episodes with high concentrations of $\mathrm{PM}_{2.5}$ and low visibility, are seen in the densely populated city cluster of the Beijing-Tianjin-Hebei region, the Sichuan basin, the Yangtze River Delta and, to a lesser extent, the Pearl River Delta. Generally, the urban air quality is worse in the north as compared with the south, and worse in the inland regions than in the coastal regions (Figure 2). There is considerable seasonal variation in $\mathrm{PM}_{2.5}$ levels, with levels being higher in winter and lower in summer. ${ }^{49}$ While smog in the capital tends to receive a good deal of media attention in China and beyond, most of the top-ranking polluted cities are in its neighbouring provinces, Hebei and Shandong. ${ }^{50} \mathrm{Li}$ and Tilt (this issue), in their study of citizens' views on air pollution in one of China's most polluted cities, Tangshan, within one of China's most polluted provinces, quote a popular Chinese saying: "If you want to see China's smog, look to Hebei; if you want to see Hebei's smog, look to Tangshan." Other megacities such as Shanghai and Guangzhou to the south have considerably lower annual mean $\mathrm{PM}_{2.5}$ levels than the worst cities in the north (in 2015, around $50 \mu \mathrm{g} / \mathrm{m}^{3}$ and $40 \mu \mathrm{g} / \mathrm{m}^{3}$, respectively, i.e. still above the Chinese air quality standard of $35 \mu \mathrm{g} / \mathrm{m}^{3}$ ).

How can we, then, summarize the general trends in Chinese cities when it comes to particulate air pollution? This is not as straightforward to determine as one might think. Only in recent years has the monitoring network established its current broad coverage. Furthermore, the metric for measuring PM has changed over time (from TSP (Total Suspended Particulates) to $\mathrm{PM}_{10}$ (see Figure 3) and only since 2013 is $\mathrm{PM}_{2.5}$ monitored on a regular basis and mainly in urban districts. Relying on monitoring data, studies indicate that urban levels of $\mathrm{PM}_{10}$ were reduced substantially in the period from around 2000 to 2012 in the north, while there was a small increase in the south during the same period. ${ }^{51}$ Generally, $\mathrm{PM}_{2.5}$ concentrations have not been decreasing at the same pace as the coarser $\mathrm{PM}_{10}$, and may even have been increasing along with reduced $\mathrm{PM}_{10}$ levels in some areas. Also, secondary particles (which are mainly in the $\mathrm{PM}_{2.5}$ fraction) seem to be playing an increasingly more important role. ${ }^{52}$ These features are linked to the fact that technologies that reduce emissions of primary particles have become more common in power plants and industries in China, whereas technologies and policies to reduce particle precursor gases $\left(\mathrm{SO}_{2}, \mathrm{NOx}, \mathrm{NH}_{3}\right.$, and VOCs (Volatile Organic Compounds) have not yet reached the same

49 Zhang and Cao 2015; Ma, Zongwei et al. 2016.

50 Greenpeace. 2015. “A summary of the 2015 annual $\mathrm{PM}_{2.5}$ city rankings," http://www.greenpeace.org/ eastasia/Global/eastasia/publications/reports/climate-energy/2015/GPEA $\% 202015 \% 20$ City $\%$ 20Rankings_briefing_int.pdf. Accessed 24 April 2016.

51 Cheng, Jiang et al. 2013.

52 Huang et al 2014; Zhao et al. 2013. 


\section{Figure 2: Annual Average $\mathbf{P M}_{2.5}$ Concentrations in China in 2015}

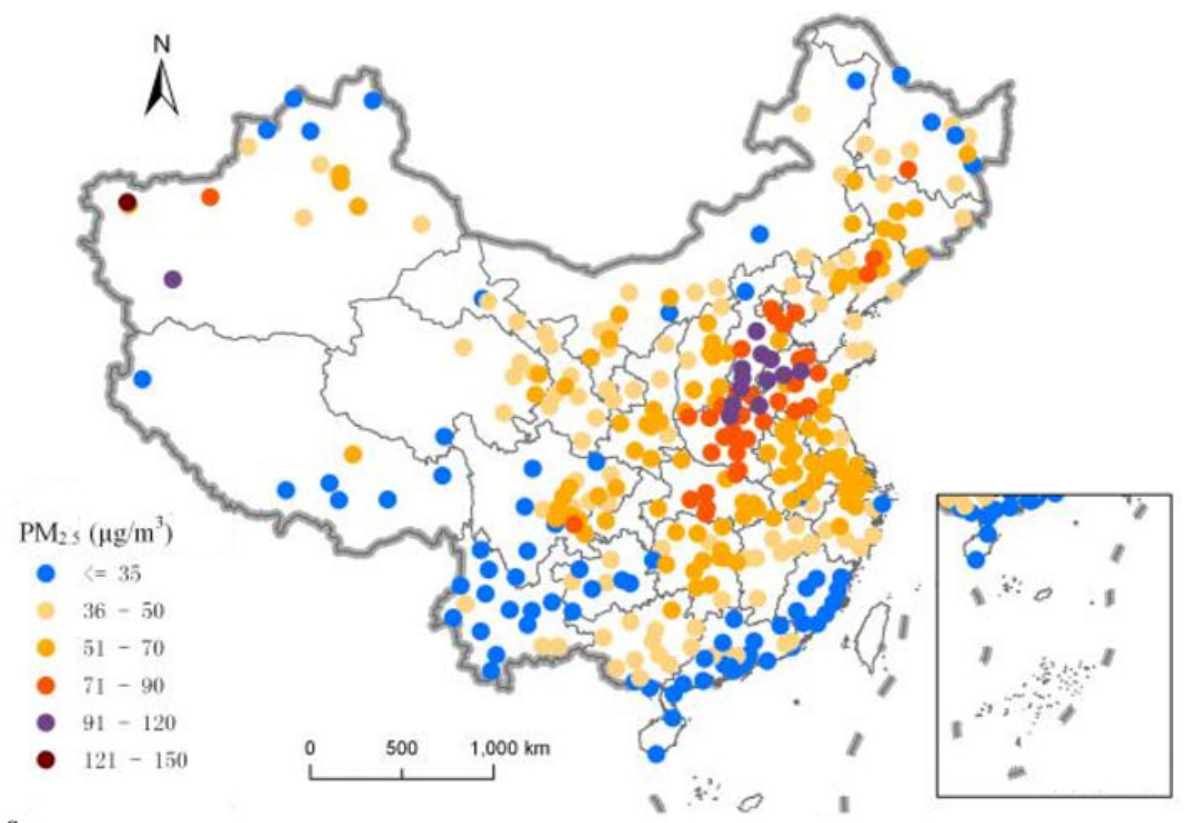

Source:

Annual average values based on hourly data downloaded from China National Environment Monitoring Center http://106.37.208.233:20035/. Accessed 27 April 2016.

coverage. A study using satellite data confirms the main pattern of hot spots for $\mathrm{PM}_{2.5}$ pollution and quantifies changes over the period 2004-2013, showing, for instance, that Hebei province was most affected. For the entire country and period, the study found a small increase in $\mathrm{PM}_{2.5}$ levels, resulting from a rise in the first years (2004-2007) followed by a smaller reduction in the period 2008$2013 .{ }^{53}$ It is important, however, to note that whereas a continued reduction in annual average levels was observed also in the period 2013-2015, several extreme smog episodes continued to occur. Moreover, according to the most recent data from the urban monitoring network, the $\mathrm{PM}_{2.5}$ levels in cities in central and western China - the regions that are seeing the highest rates of industrial growth - appear to be increasing along with the decline in northern and eastern parts of the country. ${ }^{54}$ Meteorological conditions may also have played a role in the increase in haze episodes since the 2010s. Typically, low wind speed and high relative humidity are "smog-prone" conditions. In eastern China, both wind speeds and precipitation have shown an overall decline, thus the area is now more prone to smog than it used to be. ${ }^{55}$ In 2015 , low wind speeds and high relative humidity probably also

54 Greenpeace 2016. Smog levels fall in China's eastern megacities, but rise in the west. http://us1. campaign-archive $2 . \mathrm{com} / ? \mathrm{u}=6585 \mathrm{f} 82 \mathrm{da} 0 \mathrm{cf} 6 \mathrm{~d} 1 \mathrm{feb} 1 \mathrm{edfd} 55 \& \mathrm{did}=9 \mathrm{cf} 74868 \mathrm{bc} \& \mathrm{e}=97353 \mathrm{~b} 9 \mathrm{~d} 62$. Accessed 27 April 2016.

55 Zhang et al. 2015. 
Figure 3: Main Terms Used to Describe Particulate Air Pollution

\author{
PM (Particulate Matter): may consist of a range of organic and inorganic \\ species.
}

TSP (Total Suspended Particulates): particles below $100 \mu \mathrm{m}$ in diameter. $\mathrm{PM}_{10}$ : a sub-fraction of TSP. Particles below $10 \mu \mathrm{m}$ in diameter; inhalable. $\mathrm{PM}_{2.5}$ : a sub-fraction of $\mathrm{PM}_{10}$. Particles below $2.5 \mu \mathrm{m}$ in diameter; respirable.

$\mathrm{PM}_{1}$ : a sub-fraction of $\mathrm{PM}_{2.5}$. Particles below $1 \mu \mathrm{m}$ in diameter (i.e. submicron).

Primary particles: particles directly emitted from sources.

Secondary aerosols (particles) are produced in the atmosphere from gases (particle precursors) as opposed to primary particles, which are emitted from sources. They are mainly particles in the $\mathrm{PM}_{2.5}$ size group. There are two types, secondary inorganic PM and secondary organic PM. The main precursor gases for secondary inorganic $\mathrm{PM}$ are sulphur dioxide $\left(\mathrm{SO}_{2}\right)$, nitrogen oxides (NOx), and ammonia $\left(\mathrm{NH}_{3}\right)$. Secondary organic $\mathrm{PM}$ (often denoted secondary organic aerosols (SOA)) are formed in the atmosphere from emissions of volatile or semi-volatile organic compounds (VOCs). Aerosol: small particles suspended in the atmosphere.

Ambient air pollution (AAP): outdoor, surface level, air pollution. Household air pollution (HAP): indoor and neighborhood/local air pollution from the use of solid cooking and heating fuels (e.g. wood, crop residues, and coal).

contributed to the bad air quality in Beijing in the last two months that led to the capital's first-ever red alert for air pollution, prompting schools and factories to close and restrictions on vehicle use to be put in place.

Regarding photochemical pollution, the long-term trend shows that surface ozone has been increasing substantially during 2003-2015 in China along with growing emissions of its two main precursor gases, NOx and VOC. ${ }^{56}$ Some 
authors, in fact, now warn that the efforts to reduce $\mathrm{PM}_{2.5}$ may aggravate the ozone problem if the reductions in the precursor gases NOx and VOCs are not carefully balanced. ${ }^{57}$ This raises the complicated issue of which abatement measures to apply where and when, and we discuss this briefly in the following section focusing on examples of how scientists have been involved in developing both short- and long-term attempts to control air pollution.

\section{Short-term Interventions vs Long-term Abatement}

In many Chinese cities, for instance Beijing and Shanghai, local emission reductions will have only a limited impact on local air quality, as there is large regional and interprovincial transport of polluted air masses. ${ }^{58}$ The importance of interprovincial transport has been clearly demonstrated in the Beijing region in recent years when great efforts were put into clearing the sky for a short period of time during large public and international events. Good examples are the Olympic Games in 2008, the APEC (Asia-Pacific Economic Cooperation) summit in 2014, and the Second World War 70th-anniversary Military Parade in September 2015. For the latter event, for instance, temporary control was implemented in power plants, on construction sites, and in more than 10,000 factories, not only in Beijing but in six neighbouring provinces as well. ${ }^{59}$ New popular terms like "APEC blue" and "military parade blue" testified to the successes of these cross-province actions.

While these short-term abatement measures may be drastic and unsustainable they are specifically implemented to cope with air pollution during events that enjoy a high political prestige, most recently the G20 in September 2016 in Hangzhou city. However, a range of long-term overarching national air pollution policies have been decided upon and local governments now have to deal with the complexities of implementing them, as discussed in detail in the article by Ahlers and Shen (this issue). The establishment of mandatory targets for emission control in the 11th Five-Year Plan (FYP) (2006-2010) was a turning point and proved effective for reducing $\mathrm{SO}_{2}$, the first air pollutant subject to a mandatory target. The 10 per cent reduction target for $\mathrm{SO}_{2}$ emissions was achieved with wide margins and was followed up in the 12th FYP (2011-2015), which set an 8 per cent mandatory target for $\mathrm{SO}_{2}$ and also included a 10 per cent mandatory target for NOx. As seen in Figure 4, $\mathrm{SO}_{2}$ emissions were reduced during the 11 th FYP period, ${ }^{60}$ whereas some other components of importance for $\mathrm{PM}_{2.5}$ pollution continued to grow.

Recent research has shown that in addition to fossil fuels and biomass, ammonia $\left(\mathrm{NH}_{3}\right)$ from livestock farming and nitrogen fertilizer application (the two

57 Liu et al. 2013.

58 Wang, Xing et al. 2014.

59 Xinhuanet. 2015. "China moves to ensure clean air for military parade," 17 August, http://news. xinhuanet.com/english/2015-08/17/c_134527293.htm. Accessed 24 April 2016.

60 Satellite data confirm a sharp drop in $\mathrm{SO}_{2}$ load over megacities and power plant sites, while also revealing increased loading over provinces with emerging economies, see Koukouli et al. 2016. 
Figure 4: Annual Emissions (in Mt) of Primary $\mathrm{PM}_{2.5}$ and Main $\mathrm{PM}_{2.5}$ Precursors in China $(2000,2005,2010,2013)$

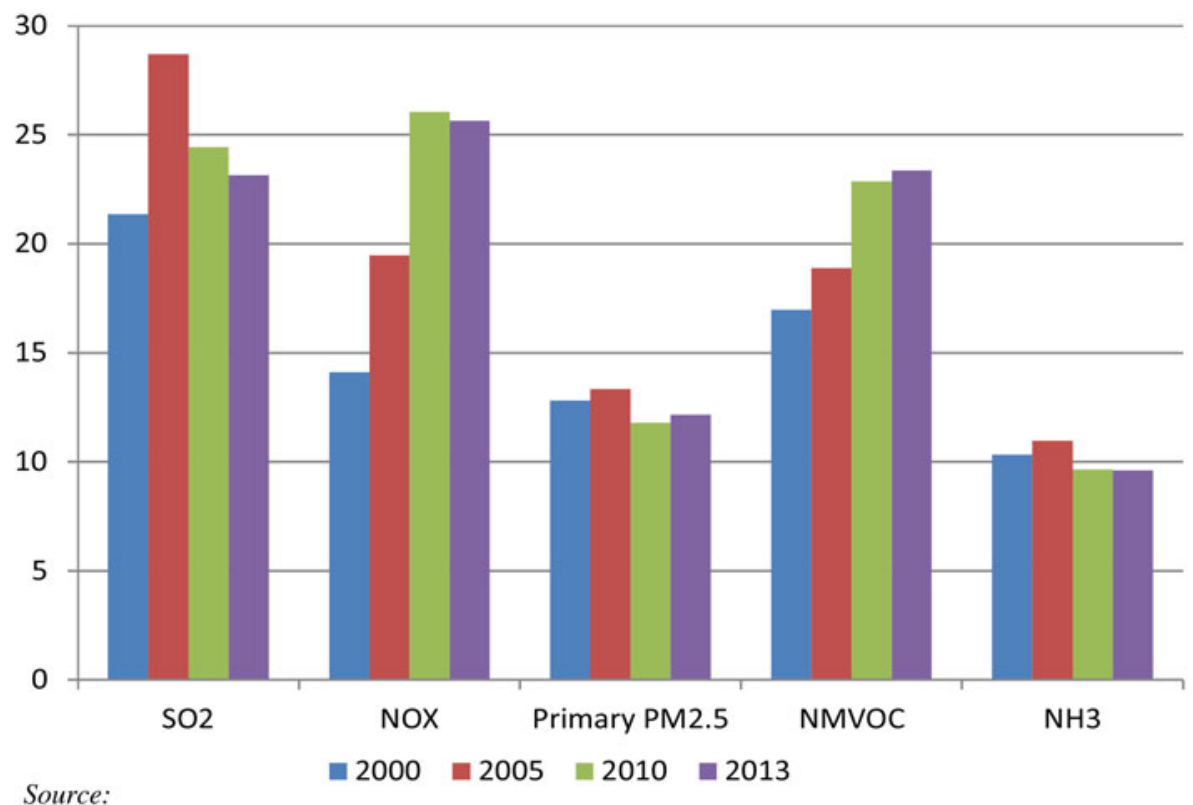

Stohl et al. 2015; Wang, Zhao et al. 2014; Ma, Qiao et al. 2016.

dominate sources of ammonia) may also play an important role in creating particulate pollution in China. Therefore, to address the complexity of air pollution formation, a multi-pollutant abatement plan aiming at reducing emissions of all main air pollutants, i.e. primary $\mathrm{PM}, \mathrm{SO}_{2}, \mathrm{NOx}, \mathrm{NH}_{3}$, and $\mathrm{VOC}$, was issued by the Chinese government in 2013 as shown in The Air Pollution Prevention and Control Plan. ${ }^{61}$ Ambitious targets were set for the most polluted regions for the period 2012-2017 with a 25 per cent, 20 per cent, and 15 per cent reduction in the $\mathrm{PM}_{2.5}$ concentrations in the Beijing-Tianjin-Hebei, Yangtze River Delta, and Pearl River Delta regions, respectively. In addition, the $\mathrm{PM}_{2.5}$ concentration in Beijing should be controlled below $60 \mu \mathrm{g} / \mathrm{m}^{3}$ - something which is a significant reduction compared to the period 2013-2015 when the level was in the range $80-90 \mu \mathrm{g} / \mathrm{m}^{3}$ in the city. According to the interim report on the evaluation of the progress in implementation of the Action Plan for Prevention and Control of Air Pollution, the policy measures taken have significantly reduced the emissions of main air pollutants and been effective in lowering $\mathrm{PM}_{2.5}$ concentrations during 2013-2015. The average concentration of $\mathrm{PM}_{2.5}$ in the 74 key cities in 2015 was down to $55 \mu \mathrm{g} / \mathrm{m}^{3}$, i.e. 23.6 per cent lower than in 2013. Satellite

61 Ministry of Environmental Protection 12.09.2013. http://english.mep.gov.cn/News_service/infocus/ 201309/t20130924_260707.htm. Accessed 26 April, 2016. See English translation: www.cleanairchina. org/file/loadFile/27.html. See Ahlers and Shen 2017 (this issue). 
monitoring also found a 10-20 per cent decline of $\mathrm{NO}_{2}$ levels and a 30-45 per cent decline of $\mathrm{SO}_{2}$ levels in the Beijing-Tianjin-Hebei, Yangtze River Delta, and Pearl River Delta regions. ${ }^{62}$

\section{Concluding Remarks: Light at the End of the Tunnel?}

As we have shown in this article, data on emissions of major air pollutants and concentration levels across China, together with estimates of the health effects associated with air pollution exposure, suggest that the worst air pollution era may belong to the past for most of the Chinese population. Nevertheless, the levels of air pollution in Chinese cities will undoubtedly remain high, well above WHO's health-based air quality guidelines for a long time to come, and the rural population residing in areas close to industry and polluted cities and still depending on solid household fuels will likely be the worst off when it comes to air pollution exposure. To reach the national air quality standard of $35 \mu \mathrm{g} / \mathrm{m}^{3}$ of $\mathrm{PM}_{2.5}$, China would need to reduce its emissions by between 50 and 70 per cent from the 2012 levels. ${ }^{63}$ However, if local governments are able to implement the central government's ambitious plans to curb air pollution through further energy transitions away from the reliance on coal, innovate and introduce new technologies, and close down outdated polluting industries, there is hope for the continued reduction of concentrations of air pollutants. Furthermore, if solutions are sought through measures other than end-of-pipe technologies (i.e. cleaning of emissions rather than reducing them at the source), the reduction of air pollution will not only have profound consequences for the health of the population, but will also serve to reduce the emission of greenhouse gases that are contributing to climate change. ${ }^{64}$

What needs more attention in this (cautiously optimistic) image of a general trend of decreasing concentrations of air pollutants in China is, for instance, the highly uneven distribution of pollution exposure. Such an approach should, in particular, include more analysis of the ways in which national policies are translated into local measures that, again, affect people differently depending on their socio-economic status, gender, options for mobility and access to knowledge and power. Finally, what cannot be ignored are the global connections of capitalism that now make it possible for China to begin pushing polluting industries towards poorer areas of the world, much as the US and Europe have done for decades. The Chinese government, like most governments in the world, seems to be set on a path of optimism regarding the possibility of combining continued economic growth with a thorough reduction of emissions of climate gasses and pollution in general. This is reflected in the state's anthropocentric vision of an

62 Interim evaluation report on implementation of Action Plan targeting air pollution, http://www.mep. gov.cn/xxgk/hjyw/201607/t20160706_357205.shtml. Accessed 10 October 2016.

63 Wang et al. 2015.

64 Aunan et al. 2006. 
Ecological Civilization and the related policy documents that, for instance, outline the requirements on local officials to continue the drive towards higher levels of economic development without endangering the environment any further, and without causing social instability. The following articles in this issue take a deeper look into the ways in which people of different social status, and with highly different levels of power and access to knowledge deal with the now thoroughly documented risks that air pollution poses to the Chinese society.

\section{Biographical notes}

Mette Halskov Hansen is professor in modern Chinese society and politics at the University of Oslo, Norway. She has published on topics such as ethnic identity, colonization of border areas, and individualization in Chinese society. During years of fieldwork in rural China she became increasingly interested in how people understand and respond to risks of pollution, what they expect from government, and how they envision their future. Recent publications include the monograph Educating the Chinese Individual (University of Washington Press 2015).

Kristin Aunan is senior research fellow at CICERO Center for International Climate Research and professor II in the department of chemistry, University of Oslo, Norway. Trained in environmental sciences, her research interests include air pollution exposure assessment and the distributional determinants of exposure and health burden. She has studied these issues in a number of interdisciplinary projects, including with colleagues in China, and publishes regularly in international journals.

Shuxiao Wang is professor of air pollution control at Tsinghua University in Beijing, China. Trained in environmental sciences, her research interests include atmospheric chemistry and physics, as well as air pollution control policies and health benefit assessment. Wang has published widely and internationally on these topics.

\section{References}

Ahlers, Anna, and Yongdong Shen. 2017. "Breathe easy? Local nuances of authoritarian environmentalism in China's battle against air pollution." The China Quarterly, special section "Human dimensions of air pollution in China."

Alnes, Line W.H., Heidi E.S.Mestl, Janne Berger, Hefeng Zhang, Shuxiao Wang, Zeqin Dong, Liying Ma et al. 2014. "Indoor PM and CO concentrations in rural Guizhou, China." Energy for Sustainable Development 21, 51-59.

Apte, Joshua S., Julian D. Marshall, Aaron J. Cohen and Michael Brauer. 2015. "Addressing global mortality from ambient PM.” Environmental Science \& Technology.

Aunan, Kristin, Jinghua Fang, Tao Hu, Hans M. Seip and Haakon Vennemo. 2006. "Climate change and air quality-measures with co-benefits in China." Environmental Science \& Technology 40 (16), 4822-9.

Aunan, Kristin, and Shuxiao Wang. 2014. "Internal migration and urbanization in China: impacts on population exposure to household air pollution (2000-2010)." Science of the Total Environment 481, 186-195. 
Austin, Jill, Peter Brimblecombe and William Sturges. 2002. Air Pollution Science for the 21st Century. Oxford, UK: Elsevier.

Bell, Michelle. L., and Devra. L. Davis. 2001. "Reassessment of the lethal London fog of 1952: novel indicators of acute and chronic consequences of acute exposure to air pollution." Environmental Health Perspectives 109, supplement 3, 389-394.

Brauer, Michael, Markus Amann, Rick T. Burnett, Aaron Cohen, Frank Dentener, Majid Ezzati, Sarah B. Henderson et al. 2012. "Exposure assessment for estimation of the global burden of disease attributable to outdoor air pollution." Environmental Science \& Technology 46(2), 652-660.

Brauer, Michael, Greg Freedman, Joseph Frostad, Aaron van Donkelaar, Randall V. Martin, Frank Dentener, Rita van Dingenen et al. 2016. "Ambient air pollution exposure estimation for the global burden of disease 2013." Environmental Science \& Technology 50(1), 79-88.

Calderon-Garciduenas, Lilian, Ricardo Torres-Jardon, Randy J. Kulesza, Su-Bin Park and Amedeo D'Angiulli. 2014. "Air pollution and detrimental effects on children's brain. The need for a multidisciplinary approach to the issue complexity and challenges." Frontiers in Human Neuroscience 8, 613.

Chafe, Zoe A., Michael Brauer, Zbigniew Klimont, Rita Van Dingenen, Sumi Mehta, Shilpa Rao, Keywan Riahi et al. 2014. "Household cooking with solid fuels contributes to ambient PM air pollution and the burden of disease." Environmental Health Perspectives.

Cheng, Zhen, Shuxiao Wang, Jingkun Jiang, Qingyan Fu, Changhong Chen, Bingye Xue, Jianqiao Yu et al. 2013. "Long-term trend of haze pollution and impact of particulate matter in the Yangtze River Delta, China." Environmental Pollution 182C, 101-110.

Cheng, Zhen, Jingkun Jiang, Oscar Fajardo, Shuxiao Wang and Jiming Hao. 2013. "Characteristics and health impacts of particulate matter pollution in China (2001-2011)." Atmospheric Environment 65, 186-194.

Duan, Xiaoli, Yong Jiang, Beibei Wang, Xiuge Zhao, Guofeng Shen, Suzhen Cao, Nan Huang et al. 2014. "Household fuel use for cooking and heating in China: results from the first Chinese Environmental Exposure-Related Human Activity Patterns Survey (CEERHAPS)." Applied Energy 136, 692-703.

Guan, Dabo, Xin Su, Qiang Zhang, Glen P. Peters, Zhu Liu, Yu Lei and Kebin He. 2014. "The socioeconomic drivers of China's primary PM2.5 emissions." Environmental Research Letters 9(2), 024010 .

Hansen, Mette Halskov, and Zhaohui Liu. 2017. "Air pollution and grassroots echoes of "ecological civilization" in rural China." The China Quarterly, special section "Human dimensions of air pollution in China."

Hoek, Gerard, Bertil Forsberg, Margaret Borowska, Stanislaw Hlawiczka, Eva Vaskovi, Hans Welinder, Martin Branis et al. 1997. "Wintertime PM10 and black smoke concentrations across Europe: results from the peace study." Atmospheric Environment 31 (21), 3609-22.

Huang, Ru-Jin, Yanlin Zhang, Carlo Bozzetti, Kin-Fai Ho, Jun-Ji Cao, Yongming Han, K. R. Daellenbach et al. 2014. "High secondary aerosol contribution to particulate pollution during haze events in China." Nature 514(7521), 218-222.

Ikeda, Kohei, Kazuyo Yamaji, Yugo Kanaya, Fumikazu Taketani, X.L. Pan, Yuichi Komazaki, Jun-ichi Kurokawa et al. 2015. "Source region attribution of PM2.5 mass concentrations over Japan.” Geochemical Journal 49(2), 185-194.

Karagulian, Federico, Claudio A. Belis, Carlos Francisco C. Dora, Annette M. Prüss-Ustün, Sophie Bonjour, Heather Adair-Rohani and Markus Amann. 2015. "Contributions to cities' ambient particulate matter (PM): a systematic review of local source contributions at global level." Atmospheric Environment 120, 475-483.

Koukouli, M.E., D.S. Balis, Ronald Johannes van der A., N. Theys, P. Hedelt, A. Richter, N. Krotkov et al. 2016. "Anthropogenic sulphur dioxide load over China as observed from different satellite sensors." Atmospheric Environment 145, 45-59. 
Lan, Qing, Robert S. Chapman, Dina M. Schreinemachers, Linwei Tian and Xingzhou He. 2002. "Household stove improvement and risk of lung cancer in Xuanwei, China." Journal of the National Cancer Institute 94(11), 826-835.

Lee, Mi Sun, Jing Qing Hang, Feng Ying Zhang, He Liang Dai, Li Su and David C. Christiani. 2012. "In-home solid fuel use and cardiovascular disease: a cross-sectional analysis of the Shanghai Putuo study." Environmental Health 11, 18.

Li, Hongtao, and Rune Svarverud. 2017. "When London hit the headlines: historical analogy and the Chinese media discourse on air pollution." The China Quarterly, special section "Human dimensions of air pollution in China."

Li, Qing, Jingkun Jiang, Shuxiao Wang, Krassi Rumchev, Ryan Mead-Hunter, Lidia Morawska and Jiming Hao. 2017. "Impacts of household coal and biomass combustion on indoor and ambient air quality in China: current status and implication." Science of the Total Environment 576, $347-361$.

Li, Xiaoyue, and Bryan Tilt. 2017. "Perceptions of quality of life and pollution among China's urban middle class: the case of smog in Tangshan." The China Quarterly, special section "Human dimensions of air pollution in China."

Liu, H., X.M. Wang, J.M. Pang and K.B. He. 2013. "Feasibility and difficulties of China's new air quality standard compliance: PRD case of PM2.5 and ozone from 2010 to 2025." Atmospheric Chemistry and Physics 13(23), 12013-27.

Liu, Jun, Denise L. Mauzerall, Qi Chen, Qiang Zhang, Yu Song, Wei Peng, Zbigniew Klimont et al. 2016. "Air pollutant emissions from Chinese households: a major and underappreciated ambient pollution source." PNAS, doi: 10.1073/pnas.1604537113.

Ma, Qiao, Siyi Cai, Shuxiao Wang, Bin Zhao, Randall V. Martin, Michael Brauer, Aaron Cohen et al. 2016. "Impacts of coal burning on ambient PM2.5 pollution in China." Atmospheric Chemistry and Physics Discussions, 1-23.

Ma, Z.Q., J. Xu, W.J. Quan, Z.Y. Zhang and W.L. Lin. 2015. "Significant increase of surface ozone at a regional background station in the eastern China." Atmospheric Chemistry and Physics Discussions 15 (21), 31951-72.

Ma, Zongwei, Xuefei Hu, Andrew M. Sayer, Robert Levy, Qiang Zhang, Yingong Xue, Shilu Tong et al. 2016. "Satellite-based spatiotemporal trends in PM2.5 concentrations: China, 2004-2013." Environmental Health Perspectives 124(2), 184-192.

Mestl, Heidi E.S., Kristin Aunan, Hans M. Seip, Shuxiao Wang, Yu Zhao and Daisheng Zhang. 2007. "Urban and rural exposure to indoor air pollution from domestic biomass and coal burning across China." Science of the Total Environment 377(1), 12-26.

Naeher, Luke P., Michael Brauer, Michael Lipsett, Judith T. Zelikoff, Christopher D. Simpson, Jane Q. Koenig and Kirk R. Smith. 2007. "Woodsmoke health effects: a review." Inhalation Toxicology 19(1), 67-106.

Peters, Glen P., Jan C. Minx, Christopher L. Weber and Ottmar Edenhofer. 2011. "Growth in emission transfers via international trade from 1990 to 2008." Proceedings of the National Academy of Sciences 108(21), 8903-08.

Seow, Wei J., Wei Hu, Roel Vermeulen, H. Dean Hosgood III, George S. Downward, Robert S. Chapman, Xingzhou He et al. 2014. "Household air pollution and lung cancer in China: a review of studies in Xuanwei." China Journal of Cancer 33(10), 471-75.

Stohl, Andreas, Borgar Aamaas, Markus Amann, Laura H. Baker, Nicolas Bellouin, Terje K. Berntsen, Olivier Boucher et al. 2015. "Evaluating the climate and air quality impacts of shortlived pollutants." Atmospheric Chemistry and Physics 15(18), 10529-66.

Temby, Owen. 2012. "American business interests meet air pollution transport science: understanding the US response to trans-Pacific air pollution.” Journal of Integrative Environmental Sciences 9(4), 219-234.

Tiao, G.C., G.E.P. Box and W.J. Hamming. 1975. "Analysis of Los Angeles photochemical smog data: a statistical overview." Journal of the Air Pollution Control Association 25(3), 260-68. 
van Donkelaar, Aaron, Randall V. Martin, Michael Brauer, Ralph Kahn, Robert Levy, Carolyn Verduzco and Paul J. Villeneuve. 2010. "Global estimates of ambient fine particulate matter concentrations from satellite-based aerosol optical depth: development and application." Environmental Health Perspectives 118(6).

Vellingiri, Kowsalya, Ki-Hyun Kim, Jong-Myoung Lim, Jin-Hong Lee, Chang-Jin Ma, Byong-Hun Jeon, Jong-Ryeul Sohn et al. 2016. "Identification of nitrogen dioxide and ozone source regions for an urban area in Korea using back trajectory analysis." Atmospheric Research 176-77, 212-221.

Wang, Rong, Shu Tao, Yves Balkanski, Philippe Ciais, Olivier Boucher, Junfeng Liu, Shilong Piao et al. 2014. "Exposure to ambient black carbon derived from a unique inventory and highresolution model." Proceedings of the National Academy of Sciences, 2459-63.

Wang, Shuxiao, and Jiming Hao. 2012. "Air quality management in China: issues, challenges, and options." Journal of Environmental Sciences 24(1), 2-13.

Wang, Shuxiao, Bin Zhao, Ye Wu and Jiming Hao. 2015. "Target and measures to prevent and control ambient fine particle pollution in China (in Chinese)." China Environment Management 2, 37-43.

Wang, Shuxiao, Bin Zhao, S.Y. Cai, Z. Klimont, C.P. Nielsen, T. Morikawa, J.H. Woo et al. 2014. "Emission trends and mitigation options for air pollutants in East Asia." Atmospheric Chemistry and Physics 14(13), 6571-603.

Wang, Shuxiao, Jia Xing, Bin Zhao, Carey Jang and Jiming Hao. 2014. "Effectiveness of national air pollution control policies on the air quality in metropolitan areas of China." Journal of Environmental Sciences 26(1), 13-22.

Wilkins, E.T. 1954. "Air pollution aspects of the London fog of December 1952 - discussion." Quarterly Journal of the Royal Meteorological Society 80(344), 267-271.

World Bank, and Institute for Health Metrics and Evaluation. 2016. The Cost of Air Pollution: Strengthening the Economic Case for Action. Washington, DC: World Bank.

Yoshitomi, M., O. Wild and H. Akimoto. 2011. "Contributions of regional and intercontinental transport to surface ozone in the Tokyo area." Atmospheric Chemistry and Physics 11(15), 7583-99.

Zhang, Junfeng (Jim), and Jonathan M. Samet. 2015. "Chinese haze versus Western smog: lessons learned." Journal of Thoracic Disease 7(1), 3-13.

Zhang, Xingying, Ling Wang, Weihe Wang, Dongjie Cao, Xi Wang and Dianxiu Ye. 2015. "Long-term trend and spatiotemporal variations of haze over China by satellite observations from 1979 to 2013." Atmospheric Environment 119, 362-373.

Zhang, Yan-Lin, and Fang Cao. 2015. "Fine particulate matter (PM2.5) in China at a city level." Scientific Reports 5, 14884.

Zhao, Bin, Shuxiao Wang, Xinyi Dong, Jiandong Wang, Lei Duan, Xiao Fu, Jiming Hao and Joshua Fu. 2013. "Environmental effects of the recent emission changes in China: implications for particulate matter pollution and soil acidification." Environmental Research Letters 8(2), 024031 .

Zhao, Yu, Shuxiao Wang, Kristin Aunan, Hans M. Seip and Jiming Hao. 2006. "Air pollution and lung cancer risks in China - a meta-analysis." Science of the Total Environment 366(2-3), 500-513.

Zheng, Jinran. 2015. "Students breathe easy in playground bubbles," 30 December, http://www. chinadaily.com.cn/china/2015-12/30/content_22863053.htm. Accessed 18 April 2016.

Zhou, Maigen, Guojun He, Maoyong Fan, Zhaoxi Wang, Yang Liu, Jing Ma, Zongwei Ma et al. 2015. "Smog episodes, fine particulate pollution and mortality in China." Environmental Research Letters 136, 396-404.

Zib, P., and E.C. Halliday. 1978. "London air pollution, 1500-1900." Atmospheric Environment (1967) 12(12), 2522. 